\title{
Hazard of Induced Overvoltage to Power Distribution Lines
}

\author{
Jiang Jun, Zhao Rui, Chen Jingyang, Tian Hua, Han Lin \\ Fushun Power Supply Company, Liaoning Electric Power Company Limited, State Grid, China \\ fushunpowersupply@163.com
}

Keywords: Overvoltage; Direct lightning; Induction thunder; Distribution Lines

\begin{abstract}
This paper based on the concept of direct lightning and induction thunder introduction, discusses the direct lightning in the calculation formula and its size (lightning over voltage amplitude is generally higher, up to tens of thousands of volts). In this paper, the calculation formula and the magnitude of the induced lightning are discussed. The amplitude of the Induction thunder overvoltage is $300 \sim 400 \mathrm{kV}$. The insulation level of power distribution line is $150 \mathrm{kV}$. When the distribution line by lightning over voltage, lightning trip rate is $100 \%$.But the distribution lines from direct lightning ratio is not high, accounting for about $3 \%$ of the total number of cases of lightning overvoltage. So the main research direction should be the distribution line induction thunder prevention. In this paper, the effect of induction thunder overvoltage on power distribution line is described by a case study. At last, this paper expounds the measures for preventing the induction thunder in the power distribution line.
\end{abstract}

\section{Introduction}

$10 \mathrm{kV}$ distribution line lightning overvoltage types into two kinds, namely direct lightning and induction thunder. There is no lightning protection line, coupling ground wire, line surge arrester and other protective measures in distribution line, coupled with the low level of insulation. Therefore, distribution lines from direct lightning, unable to defend. Direct lightning over voltage amplitude is generally higher. The voltage value is up to hundreds of kilovolts, lightning current values up to several thousands. So the direct lightning stroke at any point in the distribution network, the electrical equipment must be damaged. Direct lightning overvoltage tripping rate is $100 \%$. But the distribution lines from direct lightning ratio is not high, accounting for about $3 \%$ of the total number of cases of lightning overvoltage[1-3].

Induction lightning overvoltage accident accounted for about $97 \%$. So the research emphasis should be on the prevention of induction thunder overvoltage. Lightning strikes near the distribution network, such as buildings, trees, and ground. Through electromagnetic induction or static induction make the distribution line induction of a high voltage. The induction voltage is superimposed with the line operating voltage, and if the line voltage value exceeds the value of the flashover voltage of the insulator or the electrical equipment, insulator will flashover discharge, equipment insulation will be broken down. When the two phase or three phase power frequency short circuit grounding, cause the line trip $[4,5]$.

\section{Direct lightning overvoltage}

The concept of direct lightning, lightning direct hit distribution line conductor, distribution rod, power distribution equipment. When lightning strikes the distribution line directly, the lightning overvoltage is very high, and the distribution line insulation level is low. Direct lightning will inevitably lead to distribution line equipment damage and accident trip.

Direct lightning over voltage value can be calculated as shown in Figure 1. When sharp current flows through the power line, the current and the voltage generated in the power line has the following relationship: (overvoltage) $\mathrm{U}=$ (shock impedance) $\mathrm{Z} *$ (lightning current) I. 


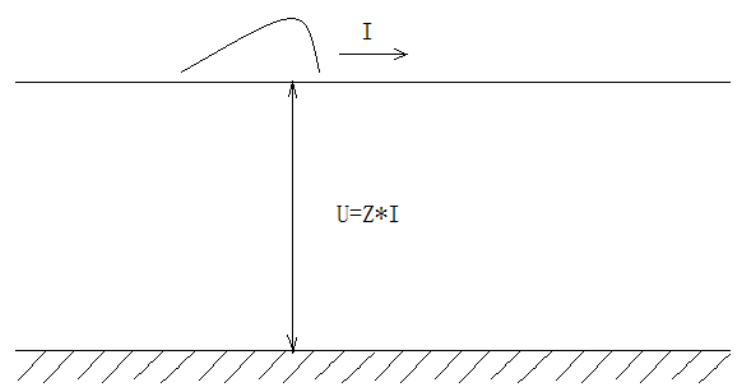

Fig.1 The relationship between lightning current and lightning overvoltage

The impact impedance of the line indicates the relationship between the line current and the line voltage (relative to the ground voltage). Impact impedance is determined by the distribution line shape (conductor section) and the line height (relative to the ground). The impact impedance value of the distribution line is usually $450 \sim 550 \Omega$.

As shown in Figure 2 below, the lightning current value of distribution lines is 20kA. On both sides of the power line, respectively, flows through the 10kA current. If the impact impedance of the distribution line is set to $500 \Omega$, then according to the formula $\mathrm{U}=\mathrm{Z} * \mathrm{I}=10 * 500=5000 \mathrm{kV}$.

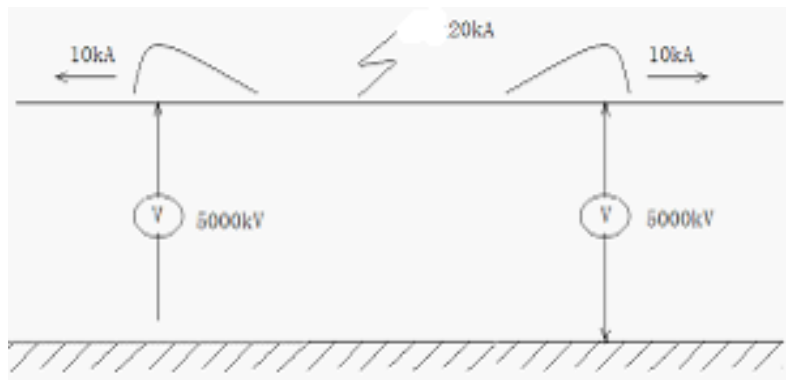

Fig.2 Direct lightning overvoltage

$5000 \mathrm{kV}$ great than the high voltage distribution lines of insulation (usually around $150 \mathrm{kV}$ ), it is easy to make the insulator discharge (insulation damage).

\section{Induction thunder overvoltage}

When lightning strikes the land near the power line, the electromagnetic induction will generate an induced overvoltage on the wire. The formation process of induced voltage as shown in Figure 3, assuming that thundercloud is negatively charged. Before the main discharge, positive charge (high ground object) began moving along the pilot channel to the thundercloud. The distribution line is in the electric field space. The electric field formed by lightning and pilot channel. Due to the electrostatic induction, the electric field strength( $\mathrm{EX}$ ) has the function to the conductive wire. The positive charge will be attracted to the wire. This section of conductor is the conductor which is the closest to the pilot channel. Positive charges become bound charges. The negative charge on the wire moves to both ends of the wire, under the action of the EX. Negative charge flows into the earth through the leakage conductance of the circuit and the neutral point of the system. Because the speed of the development of the pilot channel is very slow, so the aggregation process of the bound charge on the wire is also slow. For the above reasons, the current value is very small and can be ignored. Without considering the power frequency voltage, the conductor will keep the zero potential, due to the neutral point of the system or the leakage resistance. After the beginning of the main discharge, the negative charge in the pilot channel is rapidly neutralized, so that the bound charge on the wire is released, to move along the two ends of the wire, thereby forming a voltage. Voltage due to the sudden disappearance of the electrostatic field generated by the charge is in the pilot channel. The voltage is called the static component of the induced overvoltage. 


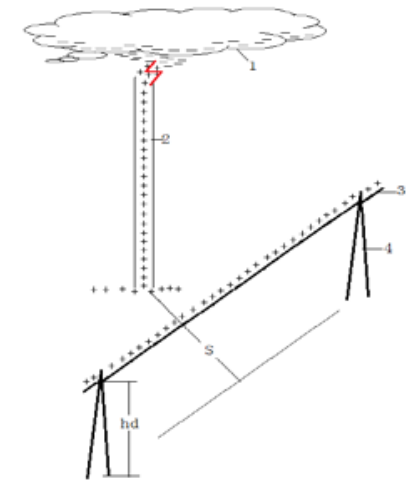

Fig.3 Schematic diagram of induced lightning overvoltage (main discharge front)

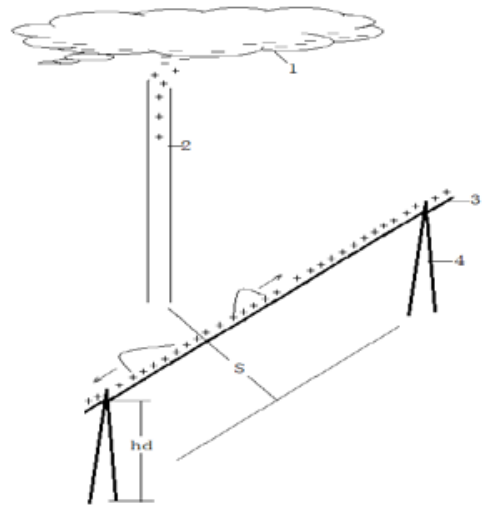

Fig.4 Schematic diagram of the induced lightning overvoltage (after the main discharge)

Note:1- thunderstorm cloud; 2- high object; 3- wire; 4- tower; Hd- conductor height;

S- Distance between towering objects and conductors;

Based on theoretical analysis and measured results. If the lightning location and the distance of the conductor is more than $65 \mathrm{~m}$, the maximum value(Ug) of lightning overvoltage can be calculated according to the following formula.

$$
\mathrm{U}_{\mathrm{g}}=25 \times \mathrm{I}_{\mathrm{L}} \times \mathrm{h}_{\mathrm{d}} / \mathrm{s}(\mathrm{kV})
$$

Type: IL. Lightning peak current (kA); hd-. Conductor height (m); s-. Distance between lightning strike position and wire (m).

Induced overvoltage is proportional to the peak value of lightning current (IL). Induced overvoltage is proportional to the average height of the wire (hd). Induced overvoltage is inversely proportional to the distance (s) of the lightning strike point to the line.

When lightning strikes the ground, the natural grounding resistance of the lightning strike point is larger. The peak value of lightning current is generally not more than 100kA. Voltage (Ug) can be estimated based on IL $(\leq 100 \mathrm{kA})$. The measured results show that the peak value of induced overvoltage is $300 \sim 400 \mathrm{kV}$. Induced lightning on the $35 \mathrm{kV}$ and the following distribution lines, can lead to insulation flashover.

\section{Distribution line accident case}

(1)Accident situation

April 27, 2014. Fushun thunderstorms. Northerly winds 5-6. The distribution line "10kV Shang Nian" line is in heavy minefield. During the period of 12:10 to 14:40, the area near the line corridor was repeatedly struck by lightning. Patrol line personnel and villagers confirmed. At 13:10 p.m., a yellow lightning hit the Mobile Corporation microwave tower. Subsequent line trip outage. Operating personnel with the telescope to see that the upper end of the microwave tower (distance from the top $0.4 \mathrm{~m}$ ) have been struck by lightning traces. In the 12\# tower, drop switch crossarm are being struck by lightning traces (Fig. 5). A phase, C phase, the line arrester is damaged. 10kV drop type switches three phase all drop off. The low voltage side metering device is badly damaged (as 
shown in Figure 6). Line power supply for microwave station has been cut off.

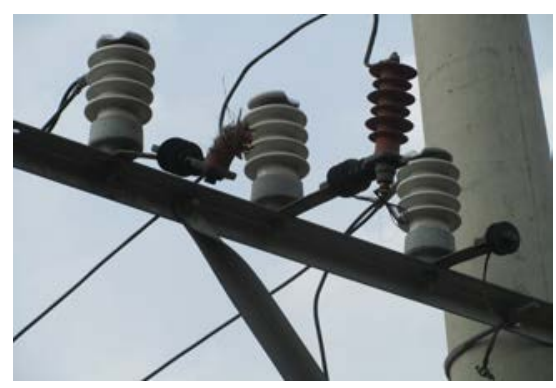

Fig.5 Lightning strike mark

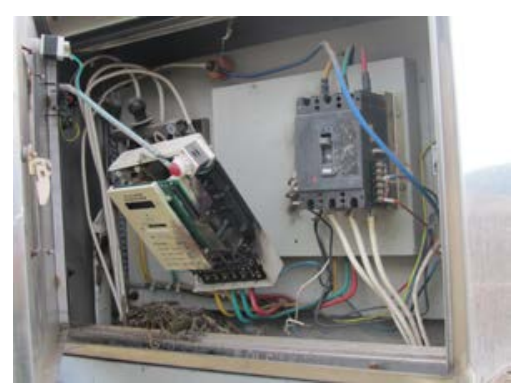

Fig.6 Low voltage side metering device is seriously damaged

(2)Accident cause analysis

The type of tower is B190-12. The type of wire is LGJ-35 type. The type of insulator is PS15 type. A drop switch is a type RW11-200/10. The type of arrester is HY5WS2-17/50TL type. Grounding resistance is $6.28 \Omega$. The type of transformer is S11-315/10. Far away from the distribution line 73 meters, there is a 70 meter high microwave tower. The height of the power line tower is 10 meters. Lightning location system shows that the microwave tower withstand the lightning current value (IL) is $100 \mathrm{kA}$.

(3)Determination of lightning overvoltage

According to the distance between the microwave tower and the line is for analysis of the accident phenomenon. The accident should belong to the category of induction thunder. From the formula of the induced lightning overvoltage:

$$
\mathrm{U}_{\mathrm{g}}=25 \times \mathrm{I}_{\mathrm{L}} \times \mathrm{h}_{\mathrm{d}} / \mathrm{s}(\mathrm{kV})=25 \times 100 \mathrm{kA} \times 10 / 73=342 \mathrm{kV}
$$

Through the damage of electrical equipment, lightning discharge traces of view and analysis. The accident is due to the microwave tower from the power distribution line is more recent (73 meters). When the microwave tower is struck by lightning, the power distribution line is subjected to induction thunder. Because the magnitude of the induced lightning over-voltage $(342 \mathrm{kV})$ exceeds the level of the insulator, so the power distribution equipment is damaged.

\section{Measures to prevent over voltage of power distribution line}

(1)The zinc oxide arrester (with outer gap) installed in all phase insulator, and to do in line with the standard grounding。

(2)A section switch or contact position of the switch in the circuit, tripping type gapless zinc oxide arrester should be installed on both sides. To avoid the lightning wave arrival switch (if the disconnect) occurs 2 times the total reflection of the wave.

(3)In the distribution transformer location, tripping type gapless $\mathrm{ZnO}$ arrester should be installed in the high voltage side of transformer. Low voltage zinc oxide lightning arrester (the corresponding voltage level) should be installed in the low-voltage side. The purpose is to prevent the forward and reverse transformer over voltage.

(4)All 5kA (current capacity) surge arrester is replaced by 10kA (current capacity) arrester. 


\section{Conclusion}

In March 14, 2014, the company for the "10kV Lang line" completed the work of lightning protection. As of July 2014, the total number of lightning overvoltage of the power distribution line is 7. The distribution line has been safe operation, there is no trip, disconnection and equipment damage.The promotion of lightning protection technology in distribution network is of great significance.

\section{Reference}

[1] Ping Shaoxun, Zhou Yufang. Analysis of Power System Neutral Point Grounding and Running. China Power Press, 2010

[2] Tan Qiong, Li Jinglu, Li Zhiqiang. Lightning Protection Technology of Mountainous Grid. China Water Power Press, 2011

[3] Yin Kening. Principle of Transformer Design. China Power Press, 2010

[4] Chen Jiabin, Gao Xiaofei. The Lightning Protection and Grounding Practical Techniques of Electrical Equipment. China Electric Power Press, 2010

[5] Zhou Zecun. High voltage technology. China Electric Power Press, 1996 